\title{
Central Bank forecasts and disclosure policy: Why it pays to be optimistic
}

\author{
Sylvester Eijffinger ${ }^{\mathrm{a}, \mathrm{b}}$, Mewael F. Tesfaselassie ${ }^{\mathrm{c}, *}$ \\ ${ }^{a}$ CentER and Department of Economics, Tilburg University, The Netherlands \\ b RSM Erasmus University, The Netherlands \\ c The Kiel Institute for the World Economy, Kiel, Germany
}

Received 25 August 2006; accepted 25 September 2006

Available online 1 November 2006

\begin{abstract}
In a model with forward-looking behavior, we study disclosure policy when a central bank has private information on the future state of the economy. We find that the effects of advance disclosure depend on the presence of uncertainty about policy targets when the shock occurs. With uncertainty about policy targets, disclosure is harmless to current outcomes, owing to the strong dependence of inflation expectations on policy actions, which induces the central bank to focus exclusively on price stability. If the central bank's targets are common knowledge, disclosure of future shocks impairs stabilization of current inflation and output.

(c) 2006 Elsevier B.V. All rights reserved.
\end{abstract}

JEL classification: E42; E43; E52; E58

Keywords: Forward-looking expectations; Private information; Central bank forecasts; Central bank disclosure; Central bank transparency

\section{Introduction}

Over the past several years, many central banks (especially those engaging in inflation targeting) have become more open about releasing their internal forecasts of the state of the economy. In this case, almost all inflation targeting central banks publish their inflation forecasts although some do not publish their output forecasts and nearly all central banks do not announce projections of their interest rate policy path (see Mishkin, 2004 for a detailed discussion). Mishkin

* Corresponding author. Dusternbrooker Weg 120, 24105 Kiel, Germany. Tel.: +494318814273; fax: +4943185853.

E-mail address: mewael.tesfaselassie@ifw-kiel.de (M.F. Tesfaselassie). 
asks whether being more transparent helps a central bank "to do its job - that is, enable it to conduct monetary policy optimally with an appropriate focus on long-run objectives?", and says that "the answer might well be no."

From the private sector's point of view, publication of central bank forecasts is welcome because for some reasons, central bank forecasts outperform those of the private sector, an indication perhaps of central bank's superior information about the future state of the economy, including the state of shocks affecting economic activity. For instance, in their empirical analysis on differences between commercial and Federal Reserve (Fed for short) forecasts, Romer and Romer (2000) conclude that "the most important finding ... is that the Federal Reserve appears to possess information about the future state of the economy that is not known to market participants." (p.455), (emphasis ours). ${ }^{1}$

The theoretical literature has explored disclosure of forecasts in the context of a discretionary monetary policy with private information about shocks to current inflation and output. ${ }^{2}$ The results are usually mixed and depend on whether there is also additional asymmetry regarding the central bank's preferences. Under a perfectly credible monetary policy, it turns out that rationalizing disclosure of forecasts is usually difficult, at least theoretically (Gersbach, 2003; Cukierman, 2001; Jensen, 2000). For instance, in a static setup that features a Lucas-type aggregate supply function, Gersbach (2003) and Cukierman (2001) show that a central bank can improve stabilization policy by withholding its private forecasts of current real shocks. Cukierman (2001) finds a similar result using a simplified version of the backward-looking model of Svensson (1997) that features time lags from the policy instrument to policy goals, and when interest rate variability enters the loss function. Crucial here is that, in both transmission mechanisms, what matters is past expectations of current inflation and the public forms expectations before policy decisions are taken.

When there are concerns about the central bank's credibility and private sector expectations respond to central bank actions, the formation of private sector expectations plays a crucial role in determining equilibrium outcomes. Geraats (2001) argues that uncertainty about the inflation target can give rise to credibility concerns. In a two-period framework, Geraats shows that, if the public uses monetary policy actions to infer the unobserved inflation target, there is an incentive for the central bank to invest in reputation in the first period in order to have more flexibility to react to shocks in the second period. This incentive is stronger the more the public knows about current period shocks that the central bank is responding to. ${ }^{3}$

However, in a two-period New-Keynesian framework that features forward-looking expectations, Jensen (2000) shows how releasing forecasts of current period shocks distorts stabilization policy, even though it solves the credibility problem arising from overambitious (unobserved) output target. Like Geraats, Jensen assumes that the public observes central bank

\footnotetext{
${ }^{1}$ In the case of the Federal Reserve, Romer and Romer (2000) discuss some of the reasons for higher quality forecasts, including inside information about future monetary policy, access to official and unofficial data, and enormous devotion of resources.

${ }^{2}$ In the terminology of Geraats (2001), the release of internal forecasts is part of what she calls economic transparency. She discusses several aspects of transparency including political (formal goals, numerical targets), economic (data, models, forecasts), operational (control errors, transmission shocks), procedural (minutes of meeting, voting), and policy (statements, inclination).

${ }^{3}$ In a cross-section study using 87 countries Chortareas et al. (2002) find that publication of forecasts reduces average inflation. Geraats and Eijffinger (2004) use time-series data on several aspects of transparency for nine major central banks, based on an index of transparency constructed by Eijffinger and Geraats (2006), and conclude that higher transparency is associated with lower short-term as well as long-term interest rates, thus lending support to the positive reputation effects of releasing forecasts, as was argued in Geraats (2001).
} 
actions before forming inflation expectations, and thus, with a high degree of transparency about current shocks, inflation expectations become extremely sensitive to the central bank's current action. But, here comes the difference, in order to stabilize inflation expectations, policy tilts heavily toward inflation stabilization, making current output very volatile. In that case, transparency could be undesirable for a central banker who enjoys good initial reputation.

This paper considers disclosure policy about central bank forecasts and, unlike the previous literature, analyzes the impact of forecasts of future shocks, as these forecasts are of interest when inflation expectations are forward-looking. The model used to analyze future shocks is based on the now familiar New-Keynesian model (see e.g., Clarida et al., 1999; King, 2000; McCallum and Nelson, 2000), which has forward-looking inflation expectations influencing current period outcomes. In this case, given the central bank's policy, a higher variability of inflation expectations (which are conditional on forecasts of future shocks) means corresponding higher variability of current inflation. This makes disclosure policy regarding forecasts of future shocks an interesting issue to study.

We find that the effects of advance disclosure of forecasts of future shocks depends on the presence of uncertainty about the central bank's preference. In line with previous studies, when there is no credibility problem and/or the central bank's preference is common knowledge, disclosure of future shocks impairs stabilization of current inflation and output. On the other hand, when there is uncertainty about the central bank's future preference shock, advance disclosure of future cost-push shocks is harmless to current inflation and output. The reason lies in the strong dependence of one-period-ahead private sector inflation forecasts on central bank actions, which induces the central bank to focus exclusively on price stability. Another implication of the paper is that when withholding forecasts of future shocks, these forecasts may not be revealed to the public by current policy actions, as the central bank prefers to stabilize the effects of private sector forecasts on current inflation.

In Section 3, we present a simple benchmark case where the central bank has full credibility and its preferences are common knowledge. In such an environment, the central bank prefers not to release information on future shocks as long as it has other goals besides price stability. With multiple goals, the central bank would like to spread the effects of adverse supply shocks on inflation and output gap, but knowing this, expected movements in future supply shocks make private sector inflation expectations to be more volatile. This effect passes to current prices through expectations of future inflation. Thus, it may be better from the perspective of the central bank not to disclose information until the private sector sets inflation expectations. This ensures that public expectations of future shocks are less volatile than when information about future shocks is available.

The benchmark case is then modified in two ways. First, instead of discretionary policy, the central bank is assumed to commit credibly to some state contingent rule (Section 4). This modification does not, however, change the result found under the benchmark case. Second, we introduce uncertainty on the part of the public regarding the central bank's preferences, which gives rise to reputation considerations (Section 5). ${ }^{4}$ The relevance of shifts in preferences depends on whether such uncertainty is directly resolved or via signaling of policy actions. It turns out that if shifts in the central bank targets have to be inferred indirectly from future central bank actions, disclosing information regarding future shocks can be harmless. Concluding remarks are given in Section 6 .

\footnotetext{
${ }^{4}$ Gersbach (2003) also concludes by emphasizing the significance of two-sided uncertainty (on preferences and knowledge), which would allow one to make more precise statements about the disclosure policies.
} 


\section{Forward-looking inflation expectations}

As we indicated in the introduction, the New-Keynesian view of the macroeconomy gives a prominent role to private sector expectations of future inflation in the determination of current inflation and output. A detailed description of the workhorse model can be found, for example, in Clarida et al. (1999) and King (2000).

Important for our analysis is the forward-looking Phillips equation determines inflation given by:

$$
\pi_{t}=\beta E_{t}^{p} \pi_{t+1}+\lambda x_{t}+u_{t}
$$

where $\pi_{t}$ is the rate of inflation, $x_{t}$ is the output gap, and $u_{t}$ is a zero-mean i.i.d (cost-push) shock to inflation $\left(u_{t} \sim N\left(0, \sigma_{u}^{2}\right)\right.$ for all $\left.t\right)$, a specification which is commonly used in the transparency literature. ${ }^{5}$ The parameters $\beta$ and $\lambda$ satisfy $0<\beta<1$ and $\lambda>0$. The term $E_{t}^{p} \pi_{t+1}$ stands for private sector (PS) expectations of next period's inflation conditional on available information at time $t$. Thus inflation depends on forward-looking PS expectations, the output gap and inflation shock. When prices are sticky, meaning that not all firms can reset their prices in every period, expectations about future prices (and therefore inflation) play an important role in determining the price level. It is the link between current inflation and expectations of future inflation that differentiates the New-Keynesian Phillips curve from the Lucas-type Phillips curve where past expectations of current inflation are important.

Likewise the dynamics of output demand is governed by a simplified version of the so called intertemporal IS equation:

$$
x_{t}=-\phi\left(i_{t}-E_{t}^{p} \pi_{t+1}\right)+v_{t}
$$

where $i_{t}$ is the nominal interest rate and $v_{t}$ is an i.i.d shock to aggregate demand. The parameter $\phi$ satisfies $\phi>0$.

The central bank (CB) chooses a sequence of short-term nominal interest rates so as to minimize the expected value of current and future losses arising from variability in inflation and output:

$$
E_{0} \sum_{t=0}^{\infty} \beta^{t} L_{t}
$$

where the period- $t$ loss function is typically given by: ${ }^{6}$

$$
L_{t}=\pi_{t}^{2}+\alpha x_{t}^{2}
$$

with $\alpha$ denoting the weight the $\mathrm{CB}$ places on output stabilization relative to inflation stabilization. For simplicity the target rate of inflation is normalized to zero. Moreover, in Section 3, the CB is

\footnotetext{
5 The recent literature on discretion and commitment in a New-Keynesian framework sometimes assumes an i.i.d specification (for instance, Woodford, 1999b). More generally, one may assume $u_{t}$ to be serially correlated without changing our main qualitative results. All that is needed for our analysis is that the central bank has a superior signal about $u_{t+1}$ than is available to the private sector.

${ }^{6}$ The quadratic loss function Eq. (4) is commonly used in monetary policy analyses. Using an optimizing microfounded model, Woodford (1999b) has shown that Eq. (4) represents a second-order approximation to the negative of the utility of a representative household. This is the reason why the discount factor $\beta$ (also present in the Phillips curve) is the same as the discount factor in the intertemporal utility function of the representative household. This correspondence, however, is not consequential for our analysis.
} 
assumed to target the equilibrium level of output gap, which is normalized to zero. We also abstract from principal-agent problems and assume the CB's loss function reflects social losses.

For $\beta \rightarrow 1$, one can scale the loss function Eq. (3) by $(1-\beta)$, which can then be approximated by the unconditional expected value of period $t$ loss (4) (see e.g., Rudebusch and Svensson, 2002):

$$
(1-\beta) E_{0} \sum_{t=0}^{\infty} \beta^{t} L_{t} \approx E\left(L_{t}\right)=\sigma_{\pi}^{2}+\alpha \sigma_{x}^{2}
$$

where $\sigma_{\pi}^{2}$ and $\sigma_{x}^{2}$ are, respectively, the unconditional variances of inflation and output gap. We will use this relationship in evaluating the expected losses arising from the regimes of transparency and non-transparency. ${ }^{7}$

\section{Observable CB preferences and disclosure policy}

The CB is assumed to have a more accurate forecast of the cost-push shock $u_{t+1}$ so that the CB can track its development better than the PS. For simplicity, the CB has perfect information about the shocks while the PS receives a noisy signal, $s_{t}$, of the shock. This assumption that the CB has full knowledge of $u_{t+1}$ is made only for convenience and is innocuous to the main message of the paper. All we need is for the CB to have a better judgement about possible future movements in the aggregate cost-push shocks. ${ }^{8}$

Except for information asymmetry regarding future shocks, there is common knowledge of the CB's loss function, including the targets for inflation and output and the preference parameter $\alpha$. In this section, we abstract from considerations of inflation bias and assume that the CB targets the equilibrium level of output, an assumption which is not unrealistic given the widely accepted assertions about the prestige of major CBs. ${ }^{9}$ The effects of uncertainty about $\mathrm{CB}$ targets and credibility issues are discussed in Section 4.

Notice from the Phillips curve that contrary to $u_{t}$, which affects $\pi_{t}$ directly, $u_{t+1}$ matters for period $t$ outcomes and policy choices only in so far as it affects price setting firm's inflation expectations. So the question basically boils down to whether firm's expectations are more or less variable in response to new information disclosed by the central bank. ${ }^{10}$

The analysis here focuses on the expectation channel, that is, on how communication of the central bank's judgment of future events affects current inflation because of changes in currently

\footnotetext{
${ }^{7}$ It is common in the literature to use the unconditional variance as the policy criterion. See e.g., McCallum and Nelson (2000) and the references therein.

8 cf. Footnote 5.

${ }^{9}$ For some forceful arguments against the literature on inflationary bias, see McCallum (1995), Blinder (1998). In the case of the Fed, Bernanke (2003), Romer and Romer (2000) discuss the reputation that the Fed has gained over the past two decades.

${ }^{10}$ We thank one of our referees for pointing us to a general setup where $u_{t+1}$ can also have an explicit role for period $t$ outcomes, a task that we plan to take up in the future. Here, we also note that, while those firms which can reset their prices benefit from information about upcoming cost-push shocks, since other firms have sticky prices, in aggregate disclosure of forecasts leads to relative price dispersion, which leads to inefficient allocation of sectoral output and consumption (Woodford (2003), p.400-401 and cf. Footnote 6). That is why a stable inflation rate (a function of stable expectations) is desirable in the New-Keynesian model used here. While in this benchmark case, more information disclosure makes expectations respond to the news, which in turn leads to more variability in actual inflation, in general one can show that the effect of expectations on current variables can differ, for example owing to control lags in the transmission of policy.
} 
held inflation expectations. The central bank's action does not inform the public about the bank's targets. One might argue that the disclosure regime about forecasts is inseparable to the credibility of the central bank's announced targets for inflation and output. The central bank's disclosure policy regarding its forecasts may be related to the fact that it wants to have flexibility to stabilize fluctuations in the economy.

\subsection{Disclosure policy under discretion}

Since the transparency regime is first announced, PS expectations will be conditional on the announced regime and the anticipated behavior of the CB. If $u_{t+1}$ is communicated to the public, inflation expectations will be conditional on $u_{t+1}$. Thus, under full transparency, the PS is not involved in signal extraction. On the other hand, if the CB does not communicate, the PS is assumed to receive a noisy signal, $s_{t}$, about $u_{t+1}:^{11}$

$$
s_{t}=u_{t+1}+\varepsilon_{t}
$$

where $\varepsilon_{t} \sim N\left(0, \sigma_{\varepsilon}^{2}\right)$ for all $t . \varepsilon_{t}$ represents the noise that contaminates the signal and is independent of $u_{t+1}$. Optimal signal extraction by the PS implies that $E_{t}^{p} u_{t+1}=k s_{t}$, where $0<k \equiv \sigma_{u}^{2} /\left(\sigma_{u}^{2}+\sigma_{\varepsilon}^{2}\right)<$ 1. Under full disclosure, the signal is useless since the PS has perfect information about $u_{t+1}$.

It is important, for future reference, to realize the fact that the unconditional variance of $k s_{t}$, given by $k^{2} \sigma_{s}^{2}$, is less than $\sigma_{u}^{2}$ :

$$
k^{2} \sigma_{s}^{2}=k \sigma_{u}^{2}<\sigma_{u}^{2}
$$

In other words, the variance of PS expectations of the shock based on the signal is less than what it would be if there was full information about the shock. This is the essence in which the CB might have an incentive not to reveal its private information about the upcoming shock.

We proceed by deriving the equilibrium outcomes under each regime and then compare the resulting losses from each regime. Here, the CB first decides about whether or not to reveal its private information and then the game is played where PS expectations are formed and the CB chooses policy taking PS expectations as given (see Cukierman, 2001 for a similar setup with Lucas-type transmission mechanism). The timing in period $t$ is:

- $u_{t}$ realizes and is commonly known.

- The CB announces the disclosure regime. Under transparency, the CB reveals $u_{t+1}$ truthfully. ${ }^{12}$

- $E_{t}^{p} \pi_{t+1}$ is formed conditional on the disclosure regime and in anticipation of the optimal policy rule of the CB.

- Given $E_{t}^{p} \pi_{t+1}$, the CB chooses the pair $\left\{x_{t}, \pi_{t}\right\}$ so as to minimize its loss function subject to the Phillips equation. ${ }^{13}$

\footnotetext{
11 As a limiting case, one could assume the PS to be completely uninformed about the cost-push shock by setting $\sigma_{\varepsilon}^{2} \rightarrow \infty$.

12 This is commonly assumed in the transparency literature since the focus of the analysis is usually on whether or not a transparent regime dominates a non-transparent one.

${ }^{13}$ For convenience the problem is solved in two steps. First, one solves for the optimal paths of inflation and output subject to Eq. (1). Then, the optimal instrument path for the nominal rate can be inferred from the IS Eq. (2). See e.g., Clarida et al. (1999).
} 
Since there are no endogenous state variables in the Phillips curve, discretionary policy implies that in each period the CB minimizes Eq. (4) given PS expectations (the term $E_{t}^{p} \pi_{t+1}$ in the Phillips Eq. (1) is treated as a fixed parameter). ${ }^{14}$ Since the CB takes PS expectations as given, the following optimality condition holds under each regime of transparency:

$$
x_{t}=-\frac{\lambda}{\alpha} \pi_{t}
$$

According to Eq. (8), in each period, the CB contracts (expands) current output in response to a higher (lower) rate of current inflation. In essence, the $\mathrm{CB}$ is reacting to any variable that directly or indirectly affects current inflation. For example if for some reasons $E_{t}^{p} \pi_{t+1}$ increases by $1 \%, \pi_{t}$ goes up by $\beta E_{t}^{p} \pi_{t+1}$, given the level of $x_{t}$. But, the optimality rule ensures that this situation does not materialize because the CB reduces $x_{t}$ to ease the burden on $\pi_{t}{ }^{15}$ The above optimality condition is related to what Lars Svensson calls a "specific targeting rule", a rule expressed in terms of the goal variables (inflation and output), and derived from a well-defined objective function. ${ }^{16}$ It should be emphasized that the targeting rule holds for all possible levels of PS expectations as perceived by the CB. The next step is to determine PS inflation expectations. Since the PS correctly anticipates the targeting rule of the CB, it knows that the dynamics of inflation is determined by Eqs. (8) and (1). Substituting Eq. (8) in Eq. (1) gives:

$$
\pi_{t}=\frac{\alpha \beta}{\alpha+\lambda^{2}} E_{t}^{p} \pi_{t+1}+\frac{\alpha}{\alpha+\lambda^{2}} u_{t}
$$

Eq. (9) shows that the evolution of actual inflation depends on currently held PS expectations about future inflation and on the current realization of the exogenous shock $u_{t}$. In this setting, $E_{t}^{p} \pi_{t+1}$ is ultimately determined by $E_{t}^{p} u_{t+1}$. Thus, the role of forecasts of the shocks is clear, and any information that improves the PS's forecast accuracy with respect to $u_{t+1}$ is valuable. The mechanism by which any private information about forecasts of future shocks affect current inflation outcomes can be shown as follows:

$$
\begin{aligned}
& \text { Disclosing } \quad u_{t+1} \rightarrow E_{t}^{p} \pi_{t+1}=f\left(u_{t+1}\right) \rightarrow \pi_{t}=g\left(u_{t+1}\right) \\
& \text { Withholding } \quad u_{t+1} \rightarrow E_{t}^{p} \pi_{t+1}=f\left(s_{t}\right) \rightarrow \pi_{t}=g\left(s_{t}\right)
\end{aligned}
$$

With this idea in mind, we can now solve the model for $E_{t}^{p} \pi_{t+1}$ and derive the rational expectations equilibrium. We first derive equilibrium inflation and output under a non-transparent regime where knowledge of $u_{t+1}$ is withheld by the CB.

\footnotetext{
${ }^{14}$ Thus, the timing of events is such that the CB chooses its interest rate policy for the current period after observing PS inflation expectations, and any advance information about current and next period shocks; see e.g., Cukierman (2001).

15 This means that $i_{t}$ should increases more than one-to-one with $E_{t}^{p} \pi_{t+1}$.

${ }^{16}$ It differs from an "instrument rule" that describes a reaction function for the nominal rate of interest (the instrument of monetary policy). See e.g., Svensson (2003).
} 


\subsubsection{Equilibrium under a non-transparent regime}

Under a non-transparent regime, the relevant state variables are $u_{t}$ and $s_{t}$. Using the commonly used method of undetermined coefficients, ${ }^{17}$ we start from Eq. (9) and guess the following solution for inflation:

$$
\pi_{t}=\theta_{1} u_{t}+\theta_{2} s_{t}=\theta_{1} u_{t}+\theta_{2}\left(u_{t+1}+\varepsilon_{t}\right)
$$

where the coefficient are yet to be determined. Without full disclosure of $u_{t+1}$, the PS resorts to its signal in forming expectations of $u_{t+1}$ :

$$
E_{t}^{p} \pi_{t+1}=\theta_{1} E_{t}^{p} u_{t+1}=\theta_{1} k s_{t}
$$

Next, replace Eq. (11) in Eq. (9) to get the following equilibrium level of inflation:

$$
\pi_{t}=\frac{\alpha \beta}{\alpha+\lambda^{2}} \theta_{1} k s_{t}+\frac{\alpha}{\alpha+\lambda^{2}} u_{t}
$$

Consistency between Eq. (12) and the guessed form Eq. (10) implies that:

$$
\pi_{t}=\theta_{1}^{*} u_{t}+\theta_{2}^{*} s_{t}
$$

where

$$
\theta_{1}^{*}=\frac{\alpha}{\alpha+\lambda^{2}} \quad \text { and } \quad \theta_{2}^{*}=\beta k \theta_{1}^{* 2}
$$

To get the solution for $x_{t}$, substitute Eq. (13) into Eq. (8):

$$
x_{t}=-\frac{\lambda}{\alpha}\left(\theta_{1}^{*} u_{t}+\theta_{2}^{*} s_{t}\right)
$$

We can now compare the resulting inflation expectations of the two parties:

$$
\begin{aligned}
& E_{t}^{c} \pi_{t+1}=\theta_{1}^{*} u_{t+1} \\
& E_{t}^{p} \pi_{t+1}=\theta_{1}^{*} k s_{t}=\theta_{1}^{*} k\left(u_{t+1}+\varepsilon_{t}\right)
\end{aligned}
$$

Taking note of Eq. (7), inflation expectations of the PS have less variability compared to those of the $\mathrm{CB}$.

\subsubsection{Equilibrium under a transparent regime}

Consider the case of transparency about $u_{t+1}$, where both parties have identical information sets. We note that under full disclosure, the conjectured solution takes the form:

$$
\pi_{t}=\theta_{1} u_{t}+\theta_{2} u_{t+1}
$$

where again the coefficients will be determined later. With full disclosure of $u_{t+1}$, rational expectations imply that:

$$
E_{t}^{p} \pi_{t+1}=\theta_{1} E_{t}^{p} u_{t+1}=\theta_{1} u_{t+1}
$$

\footnotetext{
${ }^{17}$ McCallum (1983) emphasizes on solving the model using only the fundamentals of the economy (in this case $u_{t}$ and $s_{t}$ ), avoiding bubble solutions. McCallum calls this the Minimal State Variables (MSV) method.
} 
Substituting Eq. (17) into Eq. (9) gives the following dynamics for inflation:

$$
\pi_{t}=\frac{\alpha \beta}{\alpha+\lambda^{2}} \theta_{1} u_{t+1}+\frac{\alpha}{\alpha+\lambda^{2}} u_{t}
$$

which looks similar to its counterpart under a non-transparent regime, except that now $u_{t+1}$ replaces $k s_{t}$. For Eq. (16) to be true it must be that:

$$
\pi_{t}=\tilde{\theta}_{1} u_{t}+\tilde{\theta}_{2} u_{t+1}
$$

where

$$
\widetilde{\theta} 1=\theta_{1}^{*} \text { and } \widetilde{\theta} 2=\beta \theta_{1}^{* 2}
$$

Then, the solution for $x_{t}$ follows immediately:

$$
x_{t}=-\frac{\lambda}{\alpha}\left(\widetilde{\theta} 1 u_{t}+\widetilde{\theta} 2 u_{t+1}\right)
$$

We can see that current inflation and output levels are affected not only by current period shocks, but also by next period shocks that are released to the public. Thus releasing information regarding $u_{t+1}$ makes current inflation and output more volatile. To show this formally using the loss function, we evaluate the unconditional variance Eq. (5) using the equilibrium levels of inflation and output under each regime. ${ }^{18}$ Let $E\left(L_{t}^{T}\right)$ and $E\left(L_{t}^{N T}\right)$ denote, respectively, the expected losses under the transparent and non-transparent regimes. Using Eqs. (9) and (14) in Eq. (5) and taking note of Eqs. (6) and (7):

$$
E\left(L_{t}^{N T}\right)=\left(1+\frac{\lambda^{2}}{\alpha}\right)\left(\theta_{1}^{* 2}+k \theta_{2}^{* 2}\right) \sigma_{u}^{2}
$$

Analogously, using Eqs. (19) and (20) in Eq. (5) and simplifying:

$$
E\left(L_{t}^{T}\right)=\left(1+\frac{\lambda^{2}}{\alpha}\right)\left(\theta_{1}^{* 2}+\theta_{2}^{* 2}\right) \sigma_{u}^{2}
$$

Since $0<k<1$, we have $E\left(L_{t}^{N T}\right) \leq E\left(L_{t}^{T}\right){ }^{19}$

Summarizing, the solutions for inflation and output depend on the degree of transparency about $u_{t+1}$. The main culprit for the increased volatility under transparency is the variation in PS inflation expectations. Thus it is optimal from the CB's point of view that the PS expects inflation in the next period be as less volatile as possible, although the reality is to the contrary. The CB knows the current error in PS forecasts but is not willing to disclose any information before period $t+1$ arrives or, equivalently, before PS expectations are set and policy actions taken.

\footnotetext{
${ }^{18}$ In equilibrium, PS and CB inflation expectations are $E_{t}^{p} \pi_{t+1}=E^{c} \pi_{t+1}=\theta_{1}^{*} u_{t+1}$, which differs from the case of secrecy as far as PS expectations are concerned.

19 This result also holds when the CB's objective includes interest rate stabilization as an additional goal (see Cukierman, 2001; Goodhart, 1998; Woodford, 1999a, among others, for discussions of interest rate stabilization).
} 


\subsection{Equilibrium interest rate behavior}

As it was indicated in the introduction, the transparency literature focuses on disclosure of current shocks. An implication of this is that current policy choices may partly reveal to the public the CB's private information. In the New-Keynesian framework with private information on future shocks, current period action does not give a signal of the CB's private information for two reasons. First, as the Phillips and IS equations show, optimal policy reacts to PS expectations of inflation and output, which under secrecy do not depend on the CB's information about $u_{t+1}$. Second, unlike $u_{t}$, which directly affects current inflation irrespective of PS expectations, the CB does not need to react to $u_{t+1}$. As can be seen from the case of secrecy (see Eqs. (18) and (14)), the information advantage of the CB with respect to $u_{t+1}$ is not revealed even ex post. Intuitively, under no disclosure policy, the PS does not know the realization of $u_{t+1}$, although it knows that the $\mathrm{CB}$ has that information. The best it can do is therefore to set expectations based on its signals.

To see the implications for the nominal interest rate of not releasing the CB forecasts of $u_{t+1}$, use the equilibrium solution for output and PS expectations in the IS equation and solve for the interest rate rule that implements optimal policy. Ignoring the demand shock $v_{t}$ for simplicity ${ }^{20}$

$$
i_{t}=\left(1+\frac{\beta \lambda \theta_{1}^{*}}{\alpha \phi}\right) \theta_{1}^{*} k s_{t}+\frac{\lambda \theta_{1}^{*}}{\alpha \phi} u_{t}
$$

Thus, in equilibrium, the rate of interest ultimately responds to current period shocks and PS signal of next period shocks. Even if the CB announces $i_{t}$, the PS cannot infer the CB's private information by observing $i_{t}$. This is true even if the PS knows the CB's loss function, including the targets for inflation and output and the relative weight on output stabilization. In this respect, Svensson (2003) argues that the best way to make the CB's forecasts observable to the public is by revealing the CB's model, information, assumptions and judgments. In previous studies on transparency of current period shocks, full knowledge of the loss function enables the PS to infer ex post the CB's private information about these shocks. In our case, revelation of the CB's loss function is not sufficient for inferring the CB's private information about future shocks because the CB knows that future shocks affect current inflation only via PS expectations. ${ }^{21}$

\subsection{Disclosure policy under limited commitment}

The classic theory of time-inconsistency in monetary policy rationalizes the high inflation period of the 1970 s by the discretionary behavior of CBs. The term "inflation bias" was coined to underscore the implication of the theory that, absent rule-based monetary policy, equilibrium inflation turns out to be above the socially optimal (target) level because of the temptation of monetary authorities (due to an overambitious output or employment target) to renege on their plans once PS expectations are set. With forward-looking expectations in the New-Keynesian view of the macroeconomy, we may have not only an inflation bias, but also a "stabilization bias" as a result of discretionary policy (Clarida et al., 1999). ${ }^{22}$ Even without the inflation bias problem, monetary authorities would like the PS to believe that policy will be strongly anti-inflationary in

\footnotetext{
${ }^{20}$ Observe that the demand shock does not give rise to a tradeoff in stabilizing inflation and output since the implied adjustment in interest rates to changes in demand shock moves output and inflation in the same direction. That is why in equilibrium, output and inflation are independent of the demand shock.

${ }^{21}$ A potential limitation of this argument is that the CB is assumed to observe PS expectations without error.

${ }^{22}$ This is in the sense of output being stabilized at the expense of inflation in the presence of cost-push shocks.
} 
the face of cost-push shocks, in the sense of stabilizing inflation by contracting aggregate demand, but once PS inflation expectations are manipulated this way, the authorities will have an incentive (if they are free to do so) not to stabilize inflation strongly, contrary to their plans. Knowing this fact, the PS will set inflation expectations such that the discretionary equilibrium is the only result.

If the $\mathrm{CB}$ cannot credibly commit to keeping inflation variability low in the future there by losing power to anchor inflation expectations, then policy ends up being discretionary, in effect minimizing current period's loss. The crucial observation we made in the case of discretionary policy is that the $\mathrm{CB}$ would like to see that fluctuations in PS inflation expectations are minimized. In this situation the $\mathrm{CB}$ will do anything that makes inflation expectations less variable. If it has private information about future developments of the economy, it will refrain from disclosing those information to the public, as we have shown in the case of cost-push shocks.

This section shows that the undesirable property of transparency about future shocks is not unique to discretionary policy. Even if the $\mathrm{CB}$ was to follow a rule-based policy, it would still favor secrecy as long as the CB's objective function includes output stabilization. The reason lies on the fact that under transparency, the tradeoff between inflation and output stabilization worsens as a result of the PS incorporating future shocks in its expectations irrespective of the CB's commitment.

\subsubsection{Commitment for a transparent $C B$}

A simple way to appreciate the gains from some form of commitment would be to consider a transparent regime about the shock $u_{t+1}$. The question is then, can the CB improve stabilization policy if it has the ability to commit to a given policy rule? The answer is, yes. To make it specific, suppose the CB can commit credibly to a simple policy rule that takes the same form as Eq. (20). Although this is a sort of limited commitment, as we have constrained the CB to follow a rule that has a particular form, it serves to show the benefits from commitment. The idea is to see if a transparent $\mathrm{CB}$ can lower its expected losses by committing to a simple rule within the same class of rules derived under discretion. Thus consider a commitment to the following rule

$$
x_{t}=-A u_{t}-B u_{t+1}
$$

where the weights $A$ and $B$ are to be chosen optimally by the CB. Then from Eq. (23) (and see Appendix) PS expectations for output and inflation follow:

$$
\begin{aligned}
& E_{t}^{p} x_{t+1}=\quad-A u_{t+1} \\
& E_{t}^{p} \pi_{t+1}=\quad(1-\lambda A) u_{t+1}
\end{aligned}
$$

These expressions show clearly that the CB's choice of a particular value for $A$ will directly affect PS inflation and output expectations, and via the Phillips and IS equations, current inflation and output. Using the expression for $E_{t}^{p} \pi_{t+1}$ in the Phillips Eq. (1) the reduced form expression for inflation, under commitment to the simple rule, will be:

$$
\pi_{t}=(1-\lambda A) u_{t}+(\beta(1-\lambda A)-\lambda B) u_{t+1}
$$

Given the choices of the values for the feedback parameters $A$ and $B$, the dynamics of output and inflation is governed by Eqs. (23) and (24). We can now express the expected loss as a function of the parameters $A$ and $B$ :

$$
E\left(L_{t}^{T}\right)=\left((1-\lambda A)^{2}+\alpha A^{2}+(\beta(1-\lambda A)-\lambda B)^{2}+\alpha B^{2}\right) \sigma_{u}^{2}
$$


The CB minimizes Eq. (25) with respect to $A$ and $B$ with the optimal values given by:

$$
\begin{aligned}
& A^{*}=\frac{\lambda\left[\lambda^{2}+\alpha\left(1+\beta^{2}\right)\right]}{\alpha \lambda^{2} \beta^{2}+\left(\alpha+\lambda^{2}\right)^{2}}=\left(1+\frac{\alpha^{2} \beta^{2}}{\left(\alpha+\lambda^{2}\right)^{2}+\alpha \beta^{2} \lambda^{2}}\right) \frac{\lambda}{\alpha+\lambda^{2}} \\
& B^{*}=\frac{\alpha \beta \lambda}{\alpha \lambda^{2} \beta^{2}+\left(\alpha+\lambda^{2}\right)^{2}}
\end{aligned}
$$

The first observation is that both of these coefficients differ from their counterparts under discretion with transparency (see Eq. (20)), showing the CB could improve up on the discretionary equilibrium by following a simple state-contingent rule that takes the same form as the discretionary solution but with different weights placed on the current versus forecasted shocks. Moreover, as long as $\alpha>0$, that is the CB cares about output stabilization, $A^{*}$ is larger than its corresponding coefficient while $B^{*}$ is smaller than its corresponding coefficient. This means that under commitment to the simple target rule Eq. (23) policy responds more aggressively to $u_{t}$ but less aggressively to $u_{t+1}$. The intuition for this result is that with partial commitment, a more aggressive policy in terms of contracting aggregate demand in reaction to current shocks leads the PS to expect aggressive policy in the next period, thus lowering their inflation expectations. This in turn dampens the effect of future shocks on current inflation. Thus, the CB can afford to be less aggressive with respect to future shocks because the PS does part of the job by adjusting its expectations. Knowing the value of $A^{*}$, the reduced-form of PS inflation expectations is:

$$
E_{t}^{p} \pi_{t+1}=\frac{H \alpha}{\alpha+\lambda^{2}} u_{t+1} ; \quad H \equiv 1-\frac{\alpha \beta^{2} \lambda^{2}}{\alpha \beta^{2} \lambda^{2}+\left(\alpha+\lambda^{2}\right)^{2}}
$$

Since $H$ satisfies $0<H<1$, PS inflation expectations respond less strongly to future shocks than is the case under discretion. This outcome arises from the CB's commitment to react more strongly to current shocks. If this commitment is credible, the PS expects a strong reaction to next period shocks when the time arrives. This in turn lowers inflation expectations and current inflation.

For equilibrium inflation we have:

$$
\pi_{t}=\frac{\alpha}{\left(\alpha+\lambda^{2}\right)+\left(\alpha+\lambda^{2}\right)^{-1} \alpha \beta^{2} \lambda^{2}} u_{t}+\frac{\alpha^{2} \beta}{\left(\alpha+\lambda^{2}\right)^{2}+\alpha \beta^{2} \lambda^{2}} u_{t+1}
$$

Note that, compared to discretion, a policy of limited commitment results in less variability in the dynamics of inflation (compare Eqs. (19) and (26)). This behavior contrasts with output, which responds more strongly $u_{t}$ but less strongly to $u_{t+1}$. Although this might make one conclude that the net effect of limited commitment on CB loss function is not clear, it should be obvious that limited commitment improves welfare. Why else would the CB choose different coefficients under limited commitment although the simple rule Eq. (23) falls under the class of rules derived from the discretionary solution? For the sake of completeness, however, we compare the expected losses in both regimes. Let $d$ denote discretion and $c$ commitment. Then:

$$
E\left(L_{t}^{T, j}\right)=Q_{T, j} \sigma_{u}^{2} ; \quad j=d, c .
$$


where

$$
Q_{T, c} \equiv \frac{\alpha^{2}\left(1+\beta^{2}\right)+\alpha \lambda^{2}}{\left(\alpha+\lambda^{2}\right)^{2}+\alpha \beta^{2} \lambda^{2}} ; \quad Q_{T, d} \equiv \frac{\alpha\left(\alpha^{2} \beta^{2}+\left(\alpha+\lambda^{2}\right)^{2}\right)}{\left(\alpha+\lambda^{2}\right)^{3}}
$$

Next, evaluating the ratio $Q_{T, d} / Q_{T, c}$ :

$$
\frac{Q_{T, d}}{Q_{T, c}}=1+\frac{\alpha^{3} \beta^{4} \lambda^{2}}{\left(\alpha\left(1+\beta^{2}\right)+\lambda^{2}\right)\left(\alpha+\lambda^{2}\right)^{3}}>1
$$

\subsubsection{The gains from secrecy under limited commitment}

What we have shown so far is that conditional on releasing internal forecasts of $u_{t+1}$ to the public, the $\mathrm{CB}$ is able to improve macroeconomic outcomes by credibly committing to a simple rule that reacts to these shocks. But, can the $\mathrm{CB}$ do even better by withholding information about $u_{t+1}$ and committing to a simpler rule? We can show that this is indeed optimal. The CB will gain by withholding information on $u_{t+1}$ and simply announcing the following policy rule:

$$
x_{t}=-A u_{t}
$$

lies in the fact that PS inflation expectations are always zero because of the policy of secrecy by the $\mathrm{CB}$, it is fairly easy to show that the CB's incentives do not change by this form of change in policy regime.

To see this, forward Eq. (27) one period and take PS expectations of $x_{t+1}$ :

$$
E_{t}^{p} x_{t+1}=-A E_{t}^{p} u_{t+1}=-A k s_{t}
$$

Moreover, PS inflation expectations are given by (see Appendix):

$$
E_{t}^{p} \pi_{t+1}=(1-\lambda A) E_{t}^{p} u_{t+1}=(1-\lambda A) k s_{t}
$$

Given PS expectations of inflation and output and the simple rule Eq. (27) followed by the CB, inflation will take the form:

$$
\pi_{t}=(1-\lambda A)\left(\beta k s_{t}+u_{t}\right)
$$

Expressing the expected loss as a function of $A$ :

$$
E\left(L_{t}^{N T}\right)=\left[\left(1+\beta^{2} k\right)(1-\lambda A)^{2}+\alpha A^{2}\right] \sigma_{u}^{2}
$$

and minimizing Eq. (28) with respect to $A$ gives the optimal value, $\tilde{A}=\lambda /\left[\left(1+\beta^{2} k\right)^{-1} \alpha+\lambda^{2}\right]$. The $\mathrm{CB}$ prefers this outcome to the policy of disclosing $u_{t+1}$ shown in the previous section. Thus if the $\mathrm{CB}$ is ever to commit to a simple rule, it will choose not to respond to $u_{t+1}$ and at the same time not be transparent about its realization.

It is possible to generalize the commitment case by considering the unconstrained (full) commitment solution, where the optimal policy rule under commitment is not constrained to take the functional form under limited commitment. In order to exploit forward-looking expectations, the $\mathrm{CB}$ commits to a path for current and future levels of inflation and the output gap that 
minimizes its intertemporal loss subject to the Phillips curve. In that case, it can be shown that the targeting rule is (see e.g., Clarida et al., 1999 for details):

$$
x_{t}=x_{t-1}-\frac{\lambda}{\alpha} \pi_{t}
$$

The above rule looks similar to the targeting rule under discretion, except that now there is an additional term, the lagged output gap, $x_{t-1}$, indicating history dependence in policy setting, which implies that future decisions will depend on current decisions. Such a commitment enables the CB to anchor PS inflation expectations more effectively. ${ }^{23}$ Here, $x_{t-1}$ enters as an additional state variable when solving the above history-dependent targeting rule and the Phillips curve for the rational expectations equilibrium. As far as forward-looking inflations expectations matter, the desirability of withholding the CB's advance information about $u_{t+1}$ holds true also when the CB has full commitment. $^{24}$

\section{Unobserved CB preferences, credibility and signaling}

This section modifies the analysis in Section 3 in two ways. First, as in Faust and Svensson (2001) and Jensen (2000), the model includes unobserved shifts in the CB's output target. This introduces an inflation bias as the output target can differ from the natural rate, assumed to be zero. In addition, the timing of events is such that the CB chooses its policy before PS inflation expectations are set. In principle, this implies that the PS can infer in part the output target from CB actions.

As will be shown below, the relevance of disclosing forecasts of future shocks is not clear cut and depends on specific assumptions about the unobserved output target. Specifically, the CB is better off by withholding its private information about future shocks if the shift in output target is observed with a one period lag. On the other hand if the output target is not revealed in subsequent periods, disclosing information is inconsequential for period- $t$ outcomes.

\subsection{A three-period model}

Suppose in period $t$ the CB has private information about the supply shock $u_{t+1}$ while $u_{t}$ is common knowledge. Somewhat similar to Jensen, (2000), the game has three periods, with the Phillips equation for period $t$ given by (without loss of generality, we ignore discounting and set $\beta=1)$ :

$$
\pi_{t}=E_{t}^{p} \pi_{t+1}+\lambda x_{t}+u_{t} \quad t=1,2,3 \quad u_{3}=0
$$

In Jensen (2000), $u_{1}$ is assumed to be private information of the CB while (implicitly) $u_{2}$ is unknown as of period 1 ; its value is set to zero as period 2 is interpreted to be the long-run. ${ }^{25}$ Since we are interested in analyzing future shocks, suppose instead that in period 1, $u_{1}$ is common knowledge while $u_{2}$ is the CB's private information. In Period 3, the economy reaches a steady state, with $u_{3}=0$, as period 3 represents the long-run.

\footnotetext{
${ }^{23}$ History dependence is closely related to the notion of 'timeless perspective' first discussed in Woodford (1999a).

${ }^{24}$ It is also interesting to see that when $\alpha=\lambda$ the above rule is identical to a rule that is derived from a discretionary policy that targets the nominal income growth (for a thorough discussion of nominal income targeting, see Hall and Mankiw (1994)).

25 Thus, in Jensen's model only the play in period 1 is relevant for the final outcomes.
} 
The CB loss function is defined over three periods:

$$
\begin{aligned}
U & =L_{1}+L_{2}+L_{3} \\
L_{t} & =\pi_{t}^{2}+\alpha\left(x_{t}-x_{t}^{*}\right)^{2} \quad t=1,2,3
\end{aligned}
$$

where $x_{t}^{*} \sim N\left(0, \sigma^{2}\right), x_{1}^{*}=0, x_{2}^{*}=x^{*}$, and $x_{3}^{*}=x_{2}^{*}$. These assumptions closely follow (Jensen, 2000).

The sequence of events and actions is as follows:

- Period 1: $u_{1}$ realizes $\rightarrow \mathrm{CB}$ knows $u_{2}$ while PS gets a signal $s_{1} \rightarrow \mathrm{CB}$ chooses $x_{1} \rightarrow E_{1}^{p} \pi_{2}$ formed $\rightarrow \pi_{1}$ determined

- Period 2: $x_{2}^{*}$ and $u_{2}$ realize; PS knows $u_{2} \rightarrow \mathrm{CB}$ chooses $x_{2} \rightarrow \mathrm{E}_{2}^{p} \pi_{3}$ formed $\rightarrow \pi_{2}$ determined

- Period 3 (full information steady state): PS observes $x^{*}, \mathrm{CB}$ chooses $x_{3} \rightarrow \pi_{3}$ determined

Since the outcomes of the play in period 2 is crucial, we allow a permanent shock to the output target in that period and assume this to be private information of the $\mathrm{CB}$, while the PS observes the shock with one period lag (that is, in period 3). To motivate our analysis, shifts in the output target of the $\mathrm{CB}$ may represent political pressures on the $\mathrm{CB}$ or changes in the composition of the decision making committee of the $\mathrm{CB} .{ }^{26}$ Thus in periods 2 , the PS faces uncertainty about the preference shock and in period 1 about $u_{2}$.

Following Jensen (2000), monetary policy is discretionary; the model is thus solved backwards starting from period 3. Since the policy horizon is finite and expectations are forwardlooking, a terminal condition for inflation expectations must be assumed for period 3 (see Jensen, 2000 in this regard). As noted above, the economy stays in a full information steady state from period 3 onwards, implying $\pi_{3}=\pi_{4}, E_{3}^{p} \pi_{4}=\pi_{4}$ and $x_{3}=0$. Consistent with this idea, we set $E_{3}^{p} \pi_{4}=\frac{\alpha}{\lambda} x_{3}^{*}=\frac{\alpha}{\lambda} x^{*}$, which will be confirmed below. ${ }^{27}$

Then the $\mathrm{CB}$ chooses $x_{3}$ in order to minimize period 3 loss:

$$
\left(\frac{\alpha}{\lambda} x^{*}+\lambda x_{3}\right)^{2}+\alpha\left(x_{3}-x^{*}\right)^{2}
$$

The optimal solution is $x_{3}=0$, which implies that:

$$
\pi_{3}=\frac{\alpha}{\lambda} x^{*}
$$

These are the steady state values for output and inflation, featuring an inflation bias as long as $x^{*}>0$. Note also that since Eq. (29) implies $E_{3}^{p} \pi_{4}=\frac{\alpha}{\lambda} x^{*}$, the conjecture for PS expectations is confirmed.

Next consider period 2. As we show below, it turns out that the effects of disclosing $u_{2}$ in period 1 depend on how the game is played in period 2 . We consider alternative scenarios based

\footnotetext{
${ }^{26}$ See e.g., Cukierman and Meltzer (1986), Faust and Svensson (2001), Jensen (2000) for similar interpretations to the preference shock.

${ }^{27}$ As Jensen rightly points out, the exact expression for the terminal condition is not that important for the choice of disclosure policy made in period 1 . This particular inflation expectations can also be derived from an infinite horizon model with full information about the loss function of the CB.
} 
on the PS's knowledge of $x^{*}$ in period 2. In the first case, the PS directly observes the CB's output target, and thus the CB's choice of $x_{2}$ does not play a signaling role about the output target. In the second case, the PS has to infer the output target from the CB's choice of $x_{2}$, giving rise to the role signaling and associated incentive effects. Thus the determination of $E_{2}^{p} \pi_{3}$, which follows from the solution for $\pi_{3}$ in Eq. (29) is crucial.

Case 1. $x^{*}$ is directly observed in period 2 .

When $x^{*}$ is common knowledge in period $2, E_{2}^{p} \pi_{3}=\alpha x^{*} / \lambda$, which is independent of $x_{2}$. Since PS inflation expectations are identical in periods 2 and 3 , the solution for $x_{2}$ is similar to that in period 3, except for the fact that $u_{2}$ is not necessarily zero. Analogous to period 3 , the solutions for $x_{2}$ and $\pi_{2}$ are 28

$$
\begin{aligned}
& x_{2}=-\frac{\lambda}{\alpha+\lambda^{2}} u_{2} \\
& \pi_{2}=\frac{\alpha}{\lambda} x^{*}+\frac{\alpha}{\alpha+\lambda^{2}} u_{2}
\end{aligned}
$$

An implication of Eq. (30) is that, in period 1 inflation expectations depend on the PS's forecast of $u_{2}$. From period 1's perspective both the CB and the PS expect $x_{2}^{*}$ to take its mean value of zero. It follows that the value of $E_{1}^{p} \pi_{2}$ depends on disclosure policy of the CB. Under full disclosure of $u_{2}, E_{1}^{p} \pi_{2}=\frac{\alpha}{\alpha+\lambda^{2}} u_{2}$, while $E_{1}^{p} \pi_{2}=\frac{\alpha}{\alpha+\lambda^{2}} k s_{1}$ if $u_{2}$ is not disclosed in period 1 and the PS has to depend on its noisy signal (see Section 3). ${ }^{+9}$ Anticipating the reaction of the PS expectations depends on disclosure policy, the $\mathrm{CB}$ chooses $x_{1}$ such that it minimizes the period 1 loss function.

When withholding information on $u_{2}$, the loss function is (assuming $u_{1}=0$ for simplicity): ${ }^{30}$

$$
E_{1}^{c}\left[\left(\frac{\alpha}{\alpha+\lambda^{2}} k s_{1}+\lambda x_{1}\right)^{2}+\alpha x_{1}^{2}\right]
$$

The first order condition with respect to $x_{1}$ gives:

$$
\begin{aligned}
& x_{1}=-\frac{\alpha \lambda}{\left(\alpha+\lambda^{2}\right)^{2}} k s_{1} \\
& \pi_{1}=\left(\frac{\alpha}{\alpha+\lambda^{2}}\right)^{2} k s_{1}
\end{aligned}
$$

${ }^{28}$ Then the CB chooses $x_{2}$ in order to minimize period 2 loss, which is given by:

$$
\left(\frac{\alpha}{\lambda} x^{*}+\lambda x_{2}+u_{2}\right)^{2}+\alpha\left(x_{2}-x^{*}\right)
$$

\footnotetext{
${ }^{29}$ Note that the problem faced by the CB in period 1 is identical to the benchmark model with common knowledge of the CB's preferences.

${ }^{30}$ One may wonder if the PS could get a signal about $u_{2}$ from the CB's choice of $x_{1}$. This is not possible as the CB would never react to $u_{2}$ in period 1 .
} 
On the other hand, when disclosing information on $u_{2}, x_{1}$ and $\pi_{1}$ are affected by $u_{2}$ via $E_{1}^{p} \pi_{2}$ :

$$
\begin{aligned}
& x_{1}=-\frac{\alpha \lambda}{\left(\alpha+\lambda^{2}\right)^{2}} u_{2} \\
& \pi_{1}=\left(\frac{\alpha}{\alpha+\lambda^{2}}\right)^{2} u_{2}
\end{aligned}
$$

which shows that, compared to Eqs. (31) and (32), inflation and output have more variability under full disclosure (cf. Eq. (7)).

It is clear that communicating $u_{2}$ to the PS in period 1 makes inflation and output more volatile. This is in line with the result in the full information benchmark (Section 3). Thus preference shocks, if observable by the public, do not change the basic message of the full information case without preference shocks. We think that a more interesting case is when the CB's preference is not directly revealed to the PS. This gives rise to incentive effects since in period 2 the $\mathrm{CB}$ takes into account the dependence of PS expectations on the action taken by the CB.

Case 2. $x^{*}$ is not directly observed in period 2

This time Eq. (29) implies that $E_{2}^{p} \pi_{3}=\alpha E_{2}^{p} x^{*} / \lambda$ since the PS needs to forecast the value of $x^{*}$. Since the relevant state variables in period 2 are $x^{*}$ and $u_{2}$, conjecture the following form for $x_{2}$ :

$$
x_{2}=h_{2} u_{2}+h_{x} x^{*}
$$

where the coefficients are yet to be determined. Since in period 2 the PS observes $x_{2}$ and $u_{2}$, it can make perfect inferences about $x^{*}$ from a signal, $s_{2}$, where:

$$
s_{2} \equiv x_{2}-h_{2} u_{2}=h_{x} x^{*}
$$

It is straightforward to see from Eq. (36) that PS expectations of $x^{*}$ given the signal $s_{2}$ is $E_{2}^{p} x^{*}=S_{x} s_{2}$ where $S_{x} \equiv 1 / h_{x}$. Then $E_{2}^{p} \pi_{3}=\alpha S_{x} s_{2} / \lambda$, and the minimization problem for period 2 is

$$
\min _{x_{2}} E_{2}^{c}\left[\left(\frac{\alpha}{\lambda} S_{x} s_{2}+\lambda x_{2}+u_{2}\right)^{2}+\alpha\left(x_{2}-x^{*}\right)^{2}\right]
$$

which leads to the following first order condition:

$$
0=E_{2}^{c}\left[\left(\frac{\alpha}{\lambda} S_{x} s_{2}+\lambda x_{2}+u_{2}\right)\left(\frac{\alpha}{\lambda} S_{x}+\lambda\right)+\alpha\left(x_{2}-x^{*}\right)\right]
$$

Using the fact that $E_{2}^{c} s_{2}=h_{x} x^{*}, x_{2}$ can be expressed as a function of $u_{2}$ and $x^{*}$. Then the undetermined coefficients must satisfy

$$
\begin{aligned}
& h_{2}=-\frac{\lambda^{2}+\alpha S_{x}}{\lambda\left(\alpha+\lambda^{2}+\alpha S_{x}\right)} \\
& h_{x}=\frac{\alpha \lambda^{2}}{\alpha \lambda^{2}+\left(\lambda^{2}+\alpha S_{x}\right)^{2}}
\end{aligned}
$$


The above two equations are solved recursively starting with $h_{x}$, which gives the solution $h_{x} \rightarrow 0$. It follows by definition that $S_{x} \rightarrow \infty$. This shows that PS expectations react very strongly to the signal $s_{2}$ (which is related one-to-one with $\mathrm{CB}$ action $x_{2}$ ). This in turn forces the CB not to respond to its preference shock $x^{*}$. Next, the first equation gives the solution for $h_{2}$ :

$$
h_{2}=-\frac{1}{\lambda}
$$

Combining the above results, equilibrium output and inflation in period 2 are

$$
\begin{aligned}
& x_{2}=-\frac{1}{\lambda} u_{2} \\
& \pi_{2}=\frac{\alpha}{\lambda} x^{*}
\end{aligned}
$$

The intuition for this result is as follows. The strong dependence of PS inflation expectations on monetary policy (the output choices) forces the $\mathrm{CB}$ to care about its reputation. Thus, the fact that expectations are now very sensitive to the policy action, $x_{2}$, induces the CB not to accommodate the preference shock to its output target, $x^{*}$.

An immediate implication of Eq. (37) is that disclosing CB forecasts of $u_{2}$ prior to the formation of inflation expectations in period 1 is harmless to period 1 outcomes of inflation and output. Disclosing $u_{2}$ in period 1 does not affect period 1 expectations of period 2's inflation rate, since it is common knowledge that the $\mathrm{CB}$ would completely offset the effect of $u_{2}$ on $\pi_{2}$.

The solutions for $x_{1}$ and $\pi_{1}$ in period 1 can now be derived. First Eq. (37) implies that $E_{1}^{p} \pi_{2}=$ $\alpha\left(E_{1}^{p} x^{*}\right) / \lambda=0$. Next, the CB solves for the optimal level of $x_{1}$ that minimizes:

$$
\left(\lambda x_{1}+u_{1}\right)^{2}+\alpha x_{1}^{2}
$$

The equilibrium output and inflation in period 1 are:

$$
x_{1}=-\frac{\lambda}{\alpha+\lambda^{2}} u_{1} \quad \pi_{1}=\frac{\alpha}{\alpha+\lambda^{2}} u_{1}
$$

where the CB optimally stabilizes period 1 shocks. Inflation expectations are firmly anchored at zero due to the anticipated behavior of the $\mathrm{CB}$, which is expected to stabilize period 2 inflation completely under preference shocks. Thus communicating $u_{2}$ to the PS in period 1 is inconsequential to the CB's loss.

\section{Summary and conclusion}

Over the past several years, many CBs have increased their level of transparency with respect to their forecasts on the state of the economy. However, the recent theory on transparency has not settled the question about welfare gains from advance disclosure of $\mathrm{CB}$ forecasts. Existing 
research has analyzed this question assuming private information about current shocks, as these shocks have direct impact on current economic variables, such as inflation and output, that a CB is interested in stabilizing. Based on this notion of private information, a few empirical studies on transparency lend support to the argument that disclosure of $\mathrm{CB}$ forecasts can enhance the reputation and flexibility of monetary policy.

This paper explores the significance of private information on future shocks, as forecasts of future shocks are crucial when inflation expectations are forward-looking. In a simple macro model with forward-looking expectations, we study disclosure policy when a CB has private information on future shocks. We find that the effects of advance disclosure of forecasts of future shocks depend on the existence of CB preference uncertainty.

In line with previous studies, when there is no credibility problem and/or the CB's preference is common knowledge, disclosure of future shocks impairs stabilization of current inflation and output. On the other hand, when there is uncertainty about the CB's future preference shock, advance disclosure of future shocks is harmless to current inflation and output. The reason lies in the strong dependence of one-period-ahead PS inflation forecasts on $\mathrm{CB}$ actions, which induces the $\mathrm{CB}$ to focus exclusively on price stability. Another implication of the paper is that when withholding forecasts of future shocks, these forecasts may not be revealed to the public by current policy actions, as the $\mathrm{CB}$ prefers to respond to PS forecasts. Thus while current shocks may be revealed by current $\mathrm{CB}$ actions, this may not be true for forecasts of future shocks. The result about the destabilizing effect of early disclosure of forecasts goes through for some alternative specifications, as long as there is full information regarding $\mathrm{CB}$ preferences. The results go through for a loss function that includes interest rate stabilization objective, on top of inflation and output; or if the $\mathrm{CB}$ targets nominal income growth, instead of inflation and output, as proposed by some economists. Moreover, whether policy is conducted under discretion or some form of commitment is inconsequential to the main result. Even though disclosing information seems counter-intuitive, as it improves the accuracy of PS inflation forecast, the negative result on welfare (under a credible CB) is a consequence of the $\mathrm{CB}$ having objectives other than price stability. With multiple macroeconomic goals, releasing internal forecasts before the public have currently formed expectations of future shocks, and thus future inflation, can actually impair overall stabilization efforts.

Our conjecture is that the results also apply if we drop rational expectations and assume in line with the learning literature that the PS and/or the CB adaptively learn about the structure of the economy, adjusting their forecasts with the arrival of new data. All that is needed for our results is that the CB has superior information about future supply shocks.

Obviously, there are some limitations of our analysis, limitations that are also shared by the literature on disclosure policy of $\mathrm{CB}$ forecasts. First, the $\mathrm{CB}$ is assumed to observe PS expectations without error. Introducing observation errors would put the $\mathrm{CB}$ at a disadvantage, and with very large errors, the $\mathrm{CB}$ may even be forced to be transparent about its private information. Second, there is no strategic manipulation of expectations by the PS, although it knows that the $\mathrm{CB}$ is responding to PS expectations. If the PS knows that the CB reacts to PS expectations, there is possible strategic behavior. Third, on the part of the $\mathrm{CB}$ there could be a manipulate private information and truthful revelation may not be feasible. As Romer and Romer (2000) have noted, even if CBs disclose their internal forecasts to the public in a timely manner, it is not clear if they would report their true forecasts, or if they adjust them so as to simply follow the markets. Fourth, it would be interesting to extend the analysis so that current and future shocks remain private information of the CB. 


\section{Appendix 1. Expected inflation when the CB adopts a policy of limited commitment}

$$
\begin{aligned}
\pi_{t} & =\lambda x_{t}+u_{t}+\beta E_{t}^{p} \pi_{t+1} \\
& =E_{t}^{p} \sum_{k=0}^{\infty} \beta^{k}\left[\lambda x_{t+k}+u_{t+k}\right] \\
& =E_{t}^{p} \sum_{k=0}^{\infty} \beta^{k}\left[\lambda\left(-A_{c} u_{t+k}-B_{c} u_{t+k+1}\right)+u_{t+k}\right] \\
& =E_{t}^{p} \sum_{k=0}^{\infty} \beta^{k}\left[\left(1-\lambda A_{c}\right) u_{t+k}-\lambda B_{c} u_{t+k+1}\right] \\
& =\left(1-\lambda A_{c}\right) u_{t}-\lambda B_{c} E_{t}^{p} u_{t+1}+\beta\left[\left(1-\lambda A_{c}\right) E_{t}^{p} u_{t+1}-\lambda B_{c} E_{t}^{p} u_{t+2}\right]+\ldots
\end{aligned}
$$

Since the shocks are white noise, PS inflation expectations when the CB fully discloses $u_{t+1}$ is given by

$$
E_{t}^{p} \pi_{t+1}=\left(1-\lambda A_{c}\right) u_{t+1}
$$

which is the expression following Eq. (23) in the main text. On the other hand, when the CB withholds information about $u_{t+1}$, PS expectations depends on the signal, $s_{t}$, about $u_{t+1}$ :

$$
E_{t}^{p} \pi_{t+1}=\left(1-\lambda A_{c}\right) k s_{t}
$$

where $0<k<1$ (see Section 3.1 in the main text).

\section{References}

Bernanke, B., 2003. Remarks by Governor Ben S. Bernanke before the money marketeers of New York university. Federal Reserve Board. February 3.

Blinder, A., 1998. Central Banking in Theory and Practice. MIT Press, Cambridge, MA.

Chortareas, G., Stasavage, D., Sterne, G., 2002. Does it pay to be transparent? International evidence from central bank forecasts. Federal Reserve Bank of St. Louis Review 84, 99-117.

Clarida, R., Gertler, M., Gali, J., 1999. The science of monetary policy: a New-Keynesian perspective. Journal of Economic Literature 37, 1661-1707.

Cukierman, A., 2001. Accountability, credibility, transparency and stabilization policy in the eurosystem. In: Wyplosz, C. (Ed.), The Impact of EMU on Europe and the Developing Countries. Oxford University Press, Oxford, pp. 40-75.

Cukierman, A., Meltzer, A., 1986. A theory of ambiguity, credibility and inflation under discretion and asymmetric information. Econometrica 54, 1099-1128.

Eijffinger, S., Geraats, P., 2006. How transparent are Central Banks? European Journal of Political Economy $22,1-21$.

Faust, J., Svensson, L., 2001. Transparency and credibility: monetary policy with unobservable goals. International Economic Review 42, 369-397.

Geraats, P., 2001. Why adopt transparency? The publication of central bank forecasts? ECB Working Paper. European Central Bank, Frankfurt.

Geraats, P., Eijffinger, S., 2004. Does central bank transparency reduce interest rates? CEPR-ESSIM Meeting Hosted by the Banco de Espana, Tarragona, Spain, 26-29 May.

Gersbach, H., 2003. On the negative social value of central banks knowledge transparency. Economics of Governance 4, 91-102.

Goodhart, C., 1998. Central bankers and uncertainty. Keynes Lecture presented to the British Academy.

Hall, R., Mankiw, G., 1994. Nominal income targeting. NBER Working Paper, vol. 4439. National Bureau of Economic Research, Cambridge MA.

Jensen, H., 2000. The optimal degree of transparency in monetary policymaking: the case of imperfect information about the cost-push shock. Unpublished paper, University of Copenhagen. 
King, R., 2000. The new IS-LM model: language, logic, and limits. Federal Reserve Bank of Richmond Economic Quarterly 86, 45-103.

McCallum, B., 1983. On non-uniqueness in rational expectations models. Journal of Monetary Economics 11, 139-168.

McCallum, B., 1995. Two fallacies concerning central bank independence. American Economic Review 85, $207-211$.

McCallum, B., Nelson, E., 2000. Timeless perspective vs. discretionary monetary policy in forward-looking models. NBER Working Paper, vol. 7915. National Bureau of Economic Research, Cambridge MA.

Mishkin, F., 2004. Can central bank transparency go too far? Paper presented at the Reserve Bank of Australia Conference on the Future of Inflation Targeting, August 9-10.

Romer, C.D., Romer, D.H., 2000. Federal reserve information and the behavior of interest rates. American Economic Review 90, 429-457.

Rudebusch, G., Svensson, L., 2002. Eurosystem monetary targeting: lessons from U.S data. European Economic Review 46, 417-442.

Svensson, L., 1997. Inflation forecast targeting: implementing and monitoring inflation targets. European Economic Review 41, 1111-1146.

Svensson, L., 2003. What is wrong with Taylor rules? Using judgment in monetary policy through targeting rules. Journal of Economic Literature 41, 426-477.

Woodford, M., 1999a. Optimal monetary policy inertia. NBER Working Paper, vol. 7261. National Bureau of Economic Research, Cambridge MA.

Woodford, M., 1999b. Commentary: how should monetary policy be conducted in an era of price stability? New Challenges for Monetary Policy. Federal Reserve Bank of Kansas City.

Woodford, M., 2003. Interest and Prices: foundations of a Theory of Monetary Policy. Princeton University Press, Princeton. 